\title{
Activation of Eosinophils Is More Closely Linked with Interleukin-5 and Nitric Oxide Production than Tumor Necrosis Factor-a and Immunoglobulin E Levels
}

\author{
Moon Hee Lee ${ }^{a}$ Jong Weon Choi ${ }^{b}$ Woo Ri Jang ${ }^{b}$ Joon Mee Kim ${ }^{c}$ \\ Jeong Hee Kim ${ }^{d}$ \\ Departments of a Internal Medicine, ${ }^{b}$ Laboratory Medicine, 'Pathology and d Pediatrics, College of Medicine, \\ Inha University, Incheon, Korea
}

Eosinophils contain several proinflammatory mediators and are implicated in the initiation of diverse inflammatory responses [1]. Eosinophil cationic protein (ECP) is produced in eosinophilic progenitors, stored in cytoplasmic granules of mature eosinophils, and released from activated eosinophils $[2,3]$.

The ratio of serum ECP concentrations to peripheral blood eosinophil counts (ECP/Eo ratio) reflects the number of ECP molecules per circulating eosinophil, which is regarded as a potential indicator of eosinophil activation $[4,5]$.

Few studies have closely examined the relationships between the activation of eosinophils and the production of nitric oxide (NOx) and cytokines. The present study investigated the associations between eosinophil activation and the levels of interleukin-5 (IL-5), tumor necrosis factor- $\alpha$ (TNF- $\alpha$ ), NOx metabolites, and allergen-specific immunoglobulin $\mathrm{E}$ (sIgE) scores.

A total of 112 patients with acute bronchial asthma (57 males and 55 females) aged 3.2-9.5 years (median 6) were investigated. Age- and gender-matched healthy subjects $(n=25)$ were evaluated as a control group, who had no evidence of allergic diseases and atopic sensitization based on skin-prick test results.

\section{KARGER}

E-Mail karger@karger.com

www.karger.com/aha
Patients were eligible if they had the following: (1) a documented clinical history of acute asthma, (2) positive results for sIgE test (aero- and/or food allergens according to the ImmunoCAP test), and (3) elevated serum total $\operatorname{IgE}$ (tIgE) levels to confirm allergy. The exclusion criteria were as follows: (1) medication history including corticosteroids or histamine antagonists, (2) concurrent systemic infection with fever $\left(>37.5^{\circ} \mathrm{C}\right)$, or (3) chronic illness.

The following parameters were measured: eosinophil parameters (ECP and ECP/Eo ratio), IgE-related parameters (sIgE score and $\operatorname{tgE}$ level), cytokines (IL-5 and TNF- $\alpha$ ), and inflammatory parameters [NOx metabolites and high-sensitivity C-reactive protein (hsCRP)].

The serum ECP concentration was measured using a solid-phase, 2-site chemiluminescent immunometric assay on an Immulite 2000 analyzer (Siemens Healthcare Diagnostics, Tarrytown, N.Y., USA). The cutoff limit for a positive serum ECP result was set at $>19 \mu \mathrm{g} / \mathrm{l}$ on the basis of the manufacturer's instruction.

sIgE was measured for 2 major inhalant allergens (Dermatophagoides pteronyssinus and D. farinae) and 2 food allergens (egg white and cow's milk) using a fluoroenzyme immunoassay system (ImmunoCAP 100, Phadia $\mathrm{AB}$, Uppsala, Sweden). sIgE concentrations $>0.35 \mathrm{kU} / \mathrm{l}$

Jong Weon Choi, $\mathrm{MD}, \mathrm{PhD}$

Department of Laboratory Medicine, Inha University Hospita

7-206, 3-ga, Shinheung-dong

Jung-gu, Incheon 400-711 (Korea)

E-Mail jwchoi@inha.ac.kr 
were considered positive. Scores (1-4) were assigned to each individual according to the number of positive results for the 4 allergens.

Serum tIgE concentrations were analyzed by an immunoradiometric assay (Coat-A-Count Total IgE IRMA, Siemens Healthcare Diagnostics), and hsCRP levels were assayed by a turbid immunoassay method using a chemical analyzer (Hitachi 7180, Hitachi, Tokyo, Japan).

NOx concentrations were determined by a reduced nicotinamide adenine dinucleotide phosphate (NADPH)dependent nitrate reductase assay. After serum nitrate was converted to nitrite by NADPH-dependent nitrate reductase, the total concentration of nitrite was determined by spectrophotometry at $540 \mathrm{~nm}$. IL- 5 and TNF- $\alpha$ were measured using commercially available enzymelinked immunosorbent assay kits (manufactured by BD Inc., San Diego, Calif., and R\&D Systems, Minneapolis, Minn., USA, for the respective cytokines). The ECP/Eo ratio was calculated with the following formula: ECP/Eo ratio $=$ serum ECP concentrations $(\mu \mathrm{g} / \mathrm{l}) /$ peripheral blood eosinophil counts $(/ \mu \mathrm{l})$.

Subjects were categorized into 1-2 groups based on the median ECP and the ECP/Eo ratio for the following patient populations: patients with ECP $\geq 39.5 \mu \mathrm{g} / \mathrm{l}$ ( $\mathrm{n}=$ $56)$ and $<39.5 \mu \mathrm{g} / \mathrm{l}(\mathrm{n}=56)$, and patients with ECP/Eo ratio $\geq 0.16(n=56)$ and $<0.16(n=56)$. Subjects were stratified into 3 further groups: ECP/Eo ratio $\geq 0.21$ ( $\mathrm{n}=$ $28)$ versus $\leq 0.08(n=28) ;$ IL $-5 \geq 31.7(n=28)$ versus $\leq 5.2$ $\mathrm{pg} / \mathrm{ml}(\mathrm{n}=28)$, and NOx $\geq 121.6(\mathrm{n}=28)$ versus $\leq 27.3$ $\mu \mathrm{mol} / \mathrm{l}(\mathrm{n}=28)$. These figures were based on the cutoff values for the 75th and 25th percentiles for ECP/Eo ratio, IL-5, and NOx of the 112 patients included in this study.

The data were analyzed using a nonparametric test (Mann-Whitney U test). Correlation coefficients were computed by the Spearman test. All $\mathrm{p}$ values $<0.05$ were considered statistically significant.

ECP concentrations and the ECP/Eo ratio were significantly higher in patients than in control subjects. Median values of IL-5 and NOx in the patient group were 9.6 $\mathrm{pg} / \mathrm{ml}$ and $42.9 \mu \mathrm{mol} / \mathrm{l}$, respectively, which significantly exceeded the values in healthy controls $(2.9 \mathrm{pg} / \mathrm{ml}$ and $19.3 \mu \mathrm{mol} / \mathrm{l}$, respectively, $\mathrm{p}<0.05)$. In contrast, no significant differences were observed in the TNF- $\alpha$ level between the 2 groups.

There were no significant differences in IL-5, NOx, sIgE score, and tIgE levels between patients with ECP $\geq 39.5 \mu \mathrm{g} / \mathrm{l}$ and $\mathrm{ECP}<39.5 \mu \mathrm{g} / \mathrm{l}$, nor between those with $\mathrm{ECP} /$ Eo ratio $\geq 0.16$ and $\mathrm{ECP} /$ Eo ratio $<0.16$ (data not shown).
However, as shown in table 1 , the group of patients with activated eosinophils (75th percentile group with ECP/Eo ratio $\geq 0.21$ ) had significantly higher IL-5 and NOx levels than patients in the nonactivated group (25th percentile group with ECP/Eo ratio $\leq 0.08 ; 14.1 \mathrm{pg} / \mathrm{ml}$ and $61.6 \mu \mathrm{mol} / \mathrm{l}$ vs. $5.2 \mathrm{pg} / \mathrm{ml}$ and $20.4 \mu \mathrm{mol} / \mathrm{l}$, respectively, $\mathrm{p}<0.05)$. These results suggest that IL-5 and NOx levels are not affected by minor activation of eosinophils, but may be affected by moderate activation of eosinophils.

IL-5 has a major role in the recruitment of neutrophils to the area of inflammation in allergic diseases [6]. Our data are in accordance with those of previous studies, which have demonstrated that serum IL- 5 concentrations were increased to a significantly greater extent in patients with acute asthma than in control subjects $[7,8]$.

In the current study, the effect of IL-5 and NOx metabolites on the activation of eosinophils was investigated. Patients with moderately increased IL-5 and NOx levels had significantly higher ECP and ECP/Eo ratios than those with lower levels of the corresponding parameters. IL-5 and NOx concentrations were significantly correlated with ECP $(r=0.33$ and 0.25 , respectively, $\mathrm{p}<0.001$ ) and $\mathrm{ECP} /$ Eo ratio $(\mathrm{r}=0.36$ and 0.30 , respectively, $\mathrm{p}<$ 0.001 ), but not with TNF- $\alpha$, sIgE score, and tIgE levels. These results imply that the activation of blood eosinophils is more closely associated with IL-5 and NOx production than TNF- $\alpha$ and SIgE score.

Interestingly, the median ECP/Eo ratios in patients with moderately decreased IL-5 $(\leq 5.2 \mathrm{pg} / \mathrm{ml})$ and NOx $(\leq 27.3 \mu \mathrm{mol} / \mathrm{l})$ levels were 0.09 and 0.08 , respectively; these values were not statistically different from those of the healthy controls ( $0.07 ; \mathrm{p}=0.24$ and 0.19 , respectively). These findings indicate that elevated ECP and ECP/Eo ratios returned to the levels of those of the control group, after excluding subjects with high IL-5 and NOx levels. It seems that IL-5 and NOx synthesis acts to regulate the activation of eosinophils.

Allergic asthma is characterized by airway inflammation with increased expression of inducible NOx synthase and overproduction of NOx $[9,10]$. In our study, serum NOx concentrations were significantly higher in asthma patients than in healthy controls, and were positively correlated with the ECP/Eo ratio. Our data corroborate partly the results of Banovcin et al. [11] showing the relationship between exhaled NOx levels and tIgE levels in asthma, although our data are not based on exhaled NOx levels but are based on serum NOx concentrations. On the other hand, several researchers have reported that there were no significant differences in NOx levels between asthmatics and control subjects [12].

Acta Haematol 2013;130:238-241

DOI: $10.1159 / 000350474$ 


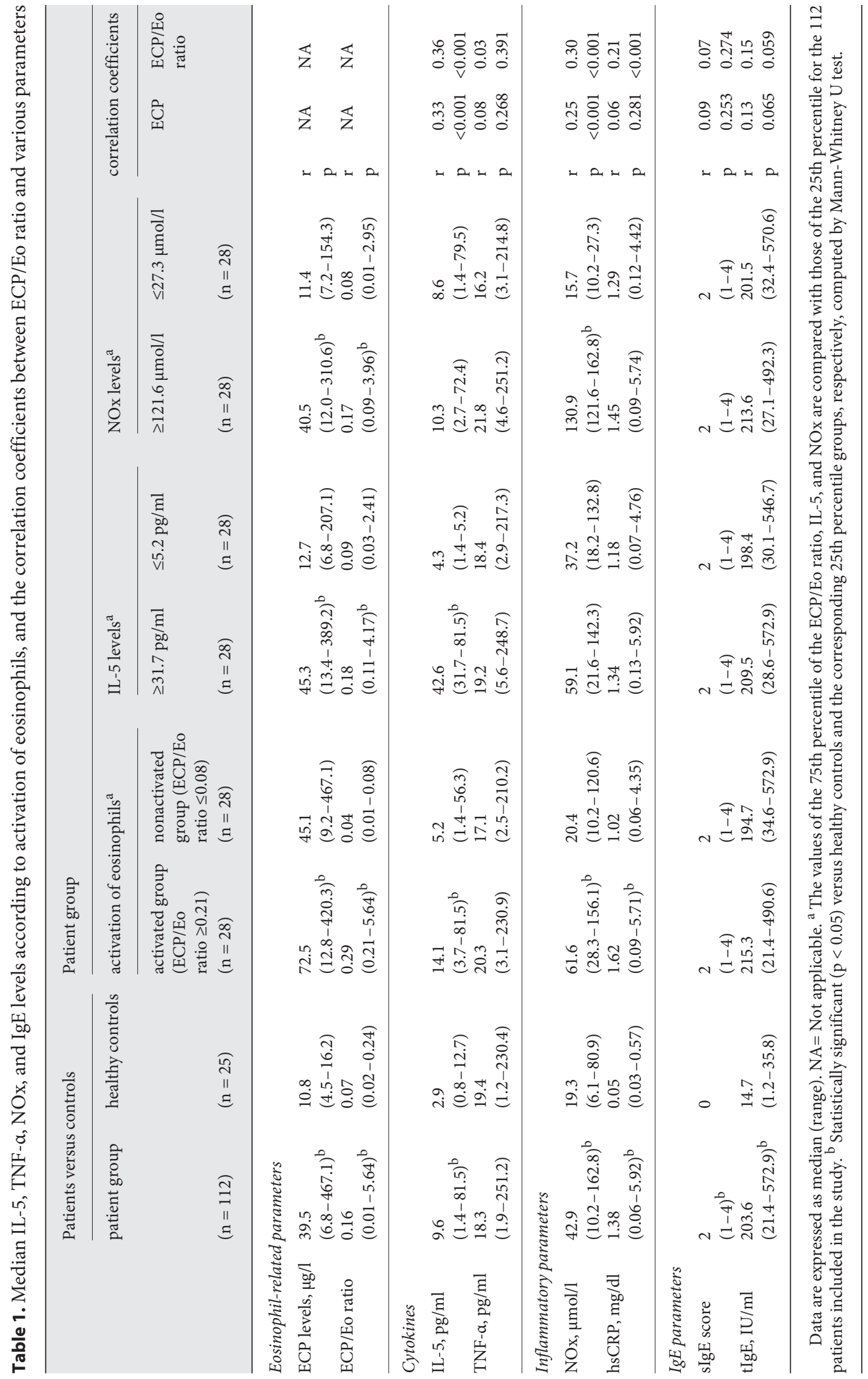


These discrepancies may reflect differences in populations of subjects and the severity of the disease among the studies. In our study, serum hsCRP levels were significantly higher in asthmatics than healthy controls. The prevalence of subclinical inflammation in conjunction with allergic disease may account for the results concerning enhanced NOx production.

In conclusion, this study shows that ECP and ECP/Eo ratio are significantly correlated with serum IL-5 and NOx concentrations, but not with TNF- $\alpha$, sIgE score, and tIgE levels. The lack of an association between $\operatorname{tgE}$ or
sIgE and the markers of eosinophil activation suggests that the activation of eosinophils is not strictly limited to the atopic sensitization and represents another aspect of allergic inflammation. Enhanced IL-5 and NOx production seems to play an important role in the activation of eosinophils as represented by the $\mathrm{ECP} /$ Eo ratio.

\section{Acknowledgement}

This study was supported by a research grant from Inha University.

\section{References}

$>1$ Wolthers OD: Eosinophil granule proteins in the assessment of airway inflammation in pediatric bronchial asthma. Pediatr Allergy Immunol 2003; 14:248-254.

$>2$ Venge P, Bystrom J, Carlson M, Hakansson L, Karawacjzyk M, Peterson C, Seveus L, Trulson A: Eosinophil cationic protein (ECP): molecular and biological properties and the use of ECP as a marker of eosinophil activation in disease. Clin Exp Allergy 1999;29: 1172-1186.

$>3$ Young JD, Peterson CG, Venge P, Cohn ZA: Mechanism of membrane damage mediated by human eosinophil cationic protein. Nature 1986;321:613-616.

4 Imai C, Yamazaki H, Tanaka Y, Matsunaga M, Numata O, Torigoe K: Ratio of eosinophil cationic protein/eosinophil count as a new marker in children with acute asthma. Pediatr Int 1999;41:142-146.
5 Fujitaka M, Kawaguchi H, Kato Y, Sakura N, Ueda K, Abe Y: Significance of the eosinophil cationic protein/eosinophil count ratio in asthmatic patients: its relationship to disease severity. Ann Allergy Asthma Immunol 2001; 86:323-329.

-6 Huang CS, Chen SJ, Chung RL, Tang RB: Serum interleukin-5 measurements for monitoring acute asthma in children. J Asthma 2005;42:297-300.

7 Oymar K, Elsayed S, Bjerknes R: Serum eosinophil cationic protein and interleukin-5 in children with bronchial asthma and acute bronchiolitis. Pediatr Allergy Immunol 1996; 7:180-186.

-8 Kato M, Yamada Y, Maruyama K, Hayashi Y: Serum eosinophil cationic protein and $27 \mathrm{cy}$ tokines/chemokines in acute exacerbation of childhood asthma. Int Arch Allergy Immunol 2010;152(suppl 1):62-66.
9 Batra J, Chatterjee R, Ghosh B: Inducible nitric oxide synthase (iNOS): role in asthma pathogenesis. Indian $\mathrm{J}$ Biochem Biophys 2007;44:303-309.

10 Wang CH, Hsieh WY, Shih LY, Lin HC, Liu CY, Chung KF, Kuo HP: Increased progenitor cell proliferation in the peripheral blood of patients with bronchial asthma: the role of nitric oxide. J Allergy Clin Immunol 1999;104: 803-810.

11 Banovcin P, Jesenak M, Michnova Z, Babusikova E, Nosal S, Mikler J, Fabry J, Barreto M: Factors attributable to the level of exhaled nitric oxide in asthmatic children. Eur J Med Res 2009;14(suppl 4):9-13.

12 Jang AS, Choi IS: Nitric oxide metabolites in patients with asthma: induced sputum versus blood. Respir Med 1999;93:912-918. 